\title{
THE ROSETTA MISSION TO PRIMITIVE BODIES OF THE
}

\author{
SOLAR SYSTEM
}

\author{
YVES LANGEVIN (ON BEHALF OF THE ROSETTA STUDY TEAM) \\ Institut d'Astrophysique Spatiale, Orsay, France \\ E-mail langevin@iaslab.span.cnes.fr
}

\begin{abstract}
The European Space Agency (ESA) has selected Rosetta as the next cornerstone mission, to be launched in 2003. The goal is to perfom one or more fly-bys to main belt asteroids, followed by a rendez-vous with an active comet. Advanced in situ analysis, both in the coma and on the surfaces of the nucleus, will be possible, as well as monitoring by remote sensing instruments of the nucleus and of the inner coma for a time span of more than one year, until perihelion. This paper outlines the scientific and technological choices done in the definition of the mission.
\end{abstract}

\section{Background}

A mission to small bodies was selected in 1983 as one of the four cornerstones of the "Horizon 2000" plan of the European Space Agency. During the first study phase, a comet nucleus sample return was studied, in the framework of an ambitious collaborative project with NASA. Following the cancellation of CRAF in early 1992, it was considered that the required NASA commitment would not be obtained for november 1993, at which time the order of implementation of the 3rd and 4th cornerstone would be selected between ROSETTA and FIRST, a submillimeter observatory mission. A new concept was th developed for ROSETTA, in which the spacecraft performs a rendez-vous with a comet after one/two asteroid fly-bys.

The highly successful close fly-bys of comet $\mathrm{P} / \mathrm{Halley}$, in 1986 , by the GIOTTO and VEGA spacecraft (more distant flybys being performed by two Japanese probes) as well as the recent observations of cometary nuclei far from the Sun provided new insights on cometary nuclei. While cometary grains are expected to represent a relevant source of micrometeoroids, interplanetary flight dynamics results in undersampling of this source among the particles entering the atmosphere (see Dermott et al., this volume), and atmospheric entry result in the loss of major fractions of the volatile and organic components in the stratospheric dust particles which can be analyzed in the laboratory. There is therefore no representative sample of cometary material. Two approaches can be considered : collecting and returning to Earth a sample from a cometary nucleus, the initial strategy proposed for ROSETTA, or performing detailed in-situ investigations on or close to the nucleus, which is the selected mission scenario.

The situation is markedly different for asteroids, the other major class of primitive bodies. While recent chaotic transfer models suggest strong selection biases, the large and diverse collections of meteorites can be considered fairly representative of the main belt of asteroids, at least of its inner regions. There are however major problems in linking the types of meteorites to specific asteroids classes. The most 
striking example is that of ordinary chondrites, the most abundant meteorite type, which have as yet no unambiguous match among asteroid classes (see Farinella et al., this volume). The major effort should therefore be devoted to document the available samples, by observing at close range main belt asteroids in their diversity. The first steps were taken during the Galileo mission, which observed two relatively small S-type asteroids, Gaspra and Ida, on its way to Jupiter (see figure at page 361 in this volume). The more primitive $\mathrm{C}$ and $\mathrm{D}$ classes, as well as the highly evolved $M$ and $V$ classes have yet to be observed.

This science rationale led to the redefinition of ROSETTA as a rendez-vous with a comet focused on in-situ investigations of cometary material, one or two asteroid fly-bys being performed during the cruise to the comet. In this way it is possible to focus the mission on the major science goals of the sample return mission (nebular condensates, presolar grains), using remote sensing investigations and state of the art in-situ analyses both in the coma and at the very surface of the nucleus. On the other hand this redefinition makes the mission feasible within the technological and budget constraints of ESA. The nominal mission can be performed with European technology (Ariane 5 launcher, solar panels, ESA $15 \mathrm{~m}$ ground stations + the German antenna at Weilheim). Scientific investigations of comet Schwassmann-Wachmann 3 (which has been selected for the baseline launch window) are performed during 16 months from the onset of activity, at nearly $4 \mathrm{AU}$ from the sun, to perihelion. With larger receiving antennas, it would be possible to observe the nucleus since rendez-vous, 5 years after launch and 3 years before perihelion. With these characteristics, ROSETTA has been selected by the Science Planning Committee as the 3rd cornerstone of ESA's long term plan, with a launch in 2003.

\section{Mission Scenario}

The ROSETTA spacecraft is launched by an Ariane 5, then performs several gravity assists in the inner solar system to obtain the required energy to reach the aphelion of the target comet, at more than 5 UA (see Tab. I).

This strategy maximizes the mass budget for missions to the outer solar system, such as GALILEO and CASSINI. A number of interesting opportunities were found, some with very high mass margins (more than $1000 \mathrm{~kg}$; see Table II). The selected nominal mission to Schwassmann-Wachmann 3 is the shortest (8 years from launch to end of mission), with a significant mass margin (more than $250 \mathrm{Kg}$ ) for the spacecraft.

During this cruise phase, which extends over 5 years, one or two asteroid flybys can be performed. The last leg of the orbit crosses the whole belt, making possible fly-bys in the mid and outer main belt of asteroids. The orbit matching manoeuvre is performed near aphelion, where the link budget is not high enough for comprehensive scientific investigations. The rendez-vous per se occurs 2 years later, when the heliocentric distance has been reduced to $3.25 \mathrm{AU}$. The following phases are implemented in the nominal mission scenario : 
TABLE I

Rosetta Comet Rendez-vous Opportunities, Launch 2003-2004.

\begin{tabular}{|c|c|c|c|c|c|c|c|c|}
\hline No. & $\begin{array}{l}\text { Rendezvous } \\
\text { with Comet }\end{array}$ & $\begin{array}{c}\text { Asteroid } \\
\text { Fly bys at }\end{array}$ & Type & $\begin{array}{c}\text { Launch } \\
\text { Arrival } \\
\text { Perihellon }\end{array}$ & $\begin{array}{c}\text { Miss. } \\
\Delta v\end{array}$ & $\begin{array}{l}\text { AR } 5 \\
\text { Perf. }\end{array}$ & $\begin{array}{l}\text { S/C at } \\
\text { Launch }\end{array}$ & Remarks \\
\hline & & & & date & $\mathrm{km} / \mathrm{s}$ & $\mathbf{k g}$ & $k_{\mathbf{g}}$ & \\
\hline 1 & $\begin{array}{l}\text { Schwassmann- } \\
\text { Wachmann } 3\end{array}$ & $\begin{array}{l}\text { Fennia } \\
1985 \text { QDI }\end{array}$ & VEE & $\begin{array}{l}2002 / 04 / 19 \\
2009 / 12 / 31 \\
2011 / 10 / 12\end{array}$ & 0.735 & 2708 & 1539 & $\begin{array}{l}\text { Early launch } \\
\text { date }\end{array}$ \\
\hline 2 & Wirtanen & $\begin{array}{c}\text { Minisstrobell } \\
\text { Shipka }\end{array}$ & MEE & $\begin{array}{l}2003 / 01 / 22 \\
2011 / 08 / 28 \\
2013 / 10 / 21\end{array}$ & 1.490 & 2990 & 1948 & \\
\hline 3 & $\begin{array}{l}\text { Schwassmann- } \\
\text { Wachınann } 3\end{array}$ & Brita & ME & $\begin{array}{l}2003 / 07 / 18 \\
2008 / 06 / 10 \\
2011 / 10 / 12\end{array}$ & 1.924 & 2426 & 2232 & $\begin{array}{l}98 \% \text { tank } \\
\text { rilling }\end{array}$ \\
\hline 4 & Finlay & 1990 OK & MTE & $\begin{array}{l}2003 / 07 / 17 \\
2013 / 09 / 05 \\
2014 / 12 / 09\end{array}$ & 1.837 & 2597 & 2172 & \\
\hline 5 & Neujmin 2 & $\begin{array}{c}1981 \text { EG } \\
\text { Virtus }\end{array}$ & VEE & $\begin{array}{l}2003 / 09 / 29 \\
2012 / 05 / 21 \\
2014 / 03 / 04\end{array}$ & 1.986 & 2499 & 2276 & $\begin{array}{l}102 \% \text { tank } \\
\text { filling }\end{array}$ \\
\hline 6 & $\begin{array}{l}\text { duToit- } \\
\text { Hartlcy }\end{array}$ & & VEE & $\begin{array}{l}2003 / 10 / 20 \\
2012 / 11 / 05 \\
2013 / 08 / 16\end{array}$ & 1.884 & 3504 & 2204 & $\begin{array}{l}\text { One or two } \\
\text { fly-bys above } \\
\text { tank filling }\end{array}$ \\
\hline 7 & Wirtanen & $\begin{array}{l}1982 \text { DX3 } \\
1983 \wedge \mathrm{D}\end{array}$ & VEE & $\begin{array}{l}2003 / 11 / 03 \\
2012 / 10 / 23 \\
2013 / 10 / 21\end{array}$ & 1.327 & 2698 & 1850 & $\begin{array}{l}\text { Rendezvous } \\
\text { at } 2.92 \wedge U\end{array}$ \\
\hline 8 & $\begin{array}{l}\text { Haneda- } \\
\text { Campos }\end{array}$ & Isis & VER & $\begin{array}{l}2003 / 11 / 21 \\
2013 / 06 / 23 \\
2016 / 11 / 08\end{array}$ & 1.465 & 2571 & 1932 & $\begin{array}{l}\text { Two fly-bys } \\
\text { bove tank } \\
\text { filling }\end{array}$ \\
\hline 9 & $\begin{array}{l}\text { Schwassniann- } \\
\text { Wachmann } 3\end{array}$ & $1990 \mathrm{TJ}$ & VE & $\begin{array}{l}2003 / 11 / 29 \\
2008 / 10 / 28 \\
2011 / 10 / 12\end{array}$ & 1.930 & 2352 & 2236 & $\begin{array}{l}98 \% \text { tank } \\
\text { filling }\end{array}$ \\
\hline 10 & Finlay & $\begin{array}{c}1982 \text { BB } \\
\text { Lunacharsky }\end{array}$ & VEE & $\begin{array}{l}2004 / 05 / 11 \\
2013 / 12 / 01 \\
2014 / 12 / 09\end{array}$ & 1.073 & 2651 & 1709 & $\begin{array}{c}\text { Maximum } \\
\text { sun distance } \\
5.8 \wedge U\end{array}$ \\
\hline 11 & Brooks 2 & $\begin{array}{c}\text { Carr } \\
1983 \text { WM }\end{array}$ & VEE & $\begin{array}{l}2004 / 05 / 25 \\
2011 / 11 / 23 \\
2014 / 05 / 23\end{array}$ & 1.740 & 2413 & 2106 & $\begin{array}{c}\text { Minimum } \\
\text { sun distance } \\
0.6 \wedge \mathrm{U}\end{array}$ \\
\hline
\end{tabular}


TABLE II

Comet opportunities, budgets and launch margins for the different mission opportunities

\begin{tabular}{|c|c|c|c|c|c|c|c|c|c|c|c|c|}
\hline \multirow[t]{2}{*}{$\mathbf{N}^{\bullet}$} & \multirow[t]{2}{*}{ Comet } & \multicolumn{2}{|l|}{ Delta V } & \multicolumn{3}{|c|}{$\begin{array}{l}\text { Propellant } \\
\text { mass }\end{array}$} & \multicolumn{2}{|c|}{ S/C Mass } & \multirow[t]{2}{*}{$\begin{array}{l}\text { Ariane } 5 \\
\text { capacity }\end{array}$} & \multirow[t]{2}{*}{$\begin{array}{l}\text { Mission } \\
\text { margin }\end{array}$} & \multirow[t]{2}{*}{$\begin{array}{l}\text { S/Cgrowth } \\
\text { capacity }\end{array}$} & \multirow[t]{2}{*}{$\begin{array}{l}\text { Tank } \\
\text { friling }\end{array}$} \\
\hline & & $\begin{array}{c}\text { Mission } \\
\mathrm{m} / \mathrm{s}\end{array}$ & $\begin{array}{l}\text { Ese } \\
\mathrm{m} / \mathrm{s}\end{array}$ & \begin{tabular}{|c|}
$400 \mathrm{~N}$ \\
Engine \\
$\mathrm{kg}$
\end{tabular} & $\begin{array}{l}\text { Attit } \\
\text { Thrus } \\
\text { Man. } \\
\text { kg }\end{array}$ & $\begin{array}{l}\text { ade } \\
\text { ters } \\
\text { WOL } \\
\text { kg }\end{array}$ & Dry & Launch & & & & \\
\hline 1 & sw 3 & 735 & 300 & 418 & 7 & 8 & 1035 & 1528 & 2708 & 1180 & 972 & $38 \%$ \\
\hline 2 & Wirtanen & 1490 & 300 & 832 & 17 & 9 & 1035 & 1952 & 2990 & 1038 & 548 & $75 \%$ \\
\hline 3 & SW 3 & 1924 & 300 & 1121 & 23 & 6 & 1035 & 2246 & 2426 & 180 & 254 & $100 \%$ \\
\hline & Finlay & 1826 & 300 & 1055 & 22 & 9 & 1035 & 2181 & 2590 & 409 & 319 & $95 \%$ \\
\hline & Neujmin 2 & 1473 & 300 & 822 & 16 & 9 & 1035 & 1943 & 2463 & 520 & 557 & $74 \%$ \\
\hline & du Toit Hartley & 1677 & 300 & 952 & 19 & 9 & 1035 & 2075 & 3234 & 1159 & 425 & $85 \%$ \\
\hline 4 & Wirtanen & 1327 & 300 & 733 & 14 & 9 & 1035 & 1851 & 2698 & 847 & 649 & $66 \%$ \\
\hline & Haneda-Campos & 1559 & 300 & 878 & 18 & 11 & 1035 & 2001 & 2568 & 567 & 499 & $79 \%$ \\
\hline 5 & Sw 3 & 1930 & 300 & 1127 & 23 & 7 & 1035 & 2252 & 2352 & 100 & 248 & $101 \%$ \\
\hline 11 & Finlay & 1073 & 300 & 590 & 11 & 9 & 1035 & 1705 & 2651 & 946 & 795 & $53 \%$ \\
\hline 12 & Brooks 2 & 1740 & 300 & 995 & 20 & 9 & 1035 & 2119 & 2413 & 294 & 381 & $89 \%$ \\
\hline
\end{tabular}

- Launch :

July 2003

Earth to Mars Cruise of 12 months

- Mars Swing-by :

July 2004

Mars to Earth Cruise of 21 months

- Earth Swing-by :

May 2006

- Fly-by of Brita :

January 2007

- Orbit matching manoeuvre with SW3

June 2008

- Comet Approach

July 2010

Science operations during 15 months

- Perihelion (End of nominal mission) October 2011

From March 2007 to July 2010, the distance from Earth to the spacecraft exceeds 3.25 UA, and the link budget is too low with the two $15 \mathrm{~m} \mathrm{ESA}$ antennas at Villafranca (Spain) and Perth (Australia). During this phase, the $30 \mathrm{~m}$ antenna in 
Weilheim (Germany) is used, in particular for the orbit matching manoeuvre. Science operations could be initiated at this stage (with some scheduling of resources for the payload) if additional $30 \mathrm{~m}$ antenna will be available in 2005 either in European networks or through a collaboration with DSN. Additional observations of the nucleus in its low activity phase could then be obtained.

The near comet operations are divided into 4 major phases :

- Detection and approach : after the orbit matching manoeuvre, the spacecraft will drift for 2 years at less than $500,000 \mathrm{Km}$ from the nucleus of Schwassmann- Wachmann 3. A bias has been included towards the Sun, which guarantees appropriate illumination of the nucleus for detection with the imaging system. After recovering the nucleus, a series of low thrust manoeuvres will be initiated, to approach the comet from the sunward side, reducing by steps the relative distance and velocity. After 90 days, the spacecraft will be at less than $100 \mathrm{Km}$ from the nucleus.

- global mapping and site selection : a global mapping phase of 20 days is scheduled at 5 to 10 comet radii from the nucleus. Such orbits are stable even for very small and irregular cometary nuclei. A resolution of 2000 pixels across the nucleus should provide an adequate data base for obtaining a detailed gravity field and rotation model of the nucleus and for selecting a few areas of interests (e.g. potentially active areas). It will then be possible to transfer to orbits with low pericenters (a few $\mathrm{Km}$ ), so as to perform high resolution observations of the selected areas. After analyzing the results, the area most likely to present volatiles at or near the surface of the nucleus will be selected for implementing the surface science module

- surface science : a surface science module will be released from the spacecraft on an orbit impacting the nucleus at very low velocities (at most a few $\mathrm{m} / \mathrm{s}$ ). Several strategies can then be considered to minimize the rebound : crushable material absorbing most of the kinetic energy, an anchoring system, or a small thruster triggered by a contact sensor. The selected trajectory will have a negative total energy relative to the nucleus, so that in any event the surface science module will eventually come to rest on the surface of the nucleus. A minimum lifetime of 5 hours is required for operating the payload (see following sections). During this lifetime, the orbit of the main spacecraft will be selected so as to remain in sight of the surface science module. If contact is not directly obtained, a search pattern will be initiated.

- monitoring of the nucleus and of activity : during a time span of at least 10 months until perihelion, the spacecraft will perform in-situ analyses of dust and gas in the inner coma as well as remote sensing observations of the nucleus and jets. All orbit modifications will be commanded from the ground, so as to take into account possible hazards as well as targets of opportunities, such as new active areas and the associated dust and gas jets. Depending on the observed dust and gas fluxes, the distance to the comet 
will be modified so as to maintain the contamination of optical surfaces and solar panels within acceptable limits. Given the relatively low activity of ROSETTA target comets with respect to $\mathrm{P} / \mathrm{Halley}$, it should be possible to remain in very close orbits (a few $\mathrm{Km}$ to a few $10 \mathrm{Km}$ ) until perihelion.

If an improved ground segment is available in 2008 - 2011 (new $30 \mathrm{~m}$ European antennas or DSN support), the first phase can start immediately after the orbit matching manoeuvre. During the following 2 years, it would then be possible to obtain comprehensive observations of the bare nucleus, and to detect a possible activity very far from the sun (which has been reported for several other comets, including $\mathrm{P} / \mathrm{Halley})$.

\section{Science Objectives}

\section{1. THE COMETARY NUCLEUS}

As indicated in the introduction, the primary science goal of ROSETTA is to obtain direct information on the chemical, mineralogical and isotopic composition of volatile and refractory cometary material, with implications on the formation of our solar system. In this context, observations of the cometary nucleus are important for two main reasons : they document the parent body in which the analyzed material formed and evolved; they provide detailed information on a surviving planetesimal from the outer parts of the solar nebula. Furthermore, such observations are essential for selecting candidate sites for the landing of a surface science package. The specific science objectives which can be addressed are the following :

- size, shape, and rotational state of the nucleus : they provide information on the history of the nucleus (cratering, sublimation), and represent key parameters for cometary activity as well as for mission planning. A resolution of 2000 pixels across the nucleus is adequate for these objectives

- mass, density, gravity field : together with the shape and rotational state, the mass and density provide constraints on the internal structure of the nucleus : can it be considered homogeneous, is there vertical layering, or is the nucleus formed from the accretion of diverse subnuclei? An important additional data would be the determination of higher moments of the gravity field, which requires orbits very close to the nucleus.

- Surface topography : the local topography, which together with rotation parameters define illumination conditions, is likely to be one of the parameters controlling activity. This issue is directly linked to the presence of ices at or close to the surface of the nucleus, and the relative role of local topography, local composition, and possible fracture zones between subnuclei needs to be evaluated. From the GIOTTO images (see Fig. 1), the size of active regions is likely to be a few $100 \mathrm{~m}$, so that characterizing the topography of these areas requires stereo imaging with a resolution of at most a few meters. 


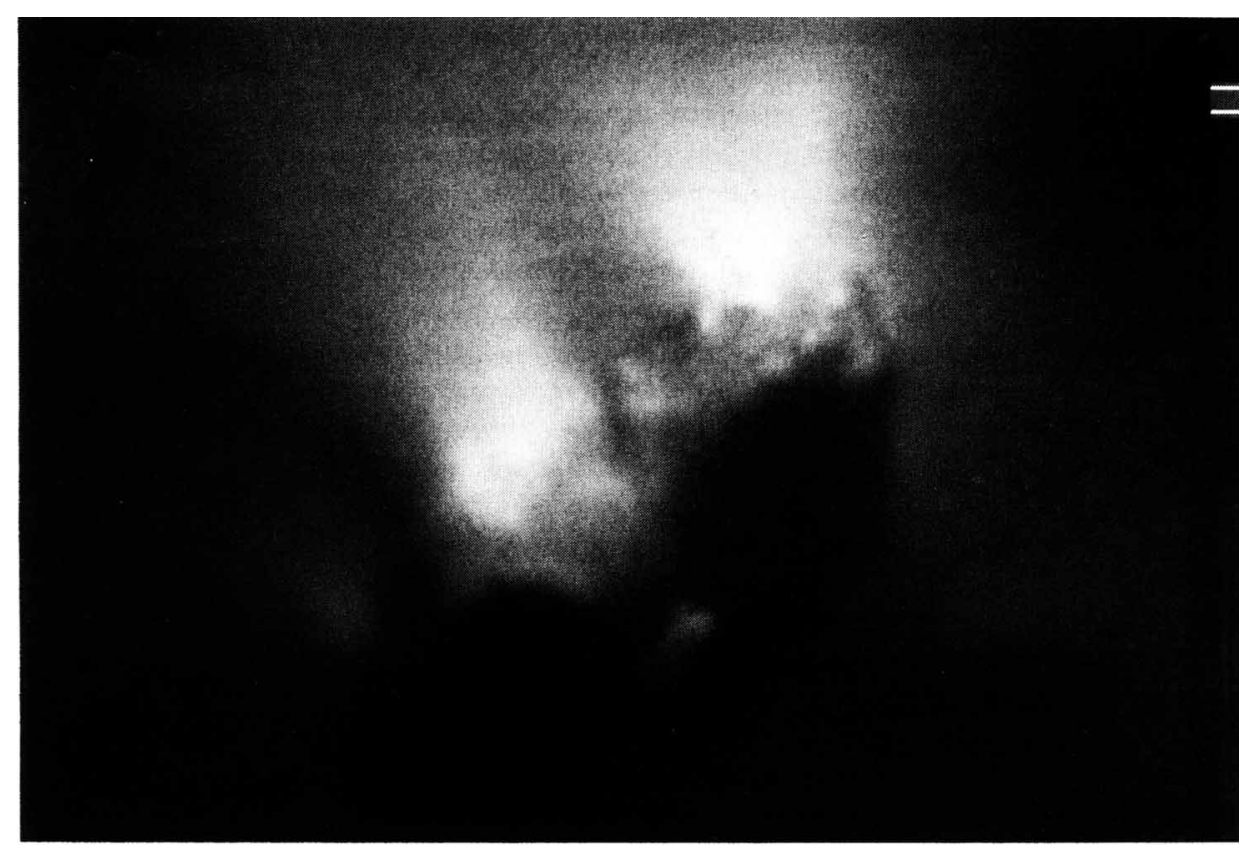

Fig. 1. Nucleus of comet P/Halley observed by GIOTTO (courtesy ESA).

- Spectral characteristics : ices, organic compounds and other major constituents of meteoritic material all present strong absorption bands in the visible and near infrared regions. In these spectral ranges, it is possible to determine whether ices are present at the very surface of the nucleus, and to obtain information on the mineralogical composition of active and non active areas. Given the typical size of active areas, a resolution of a few $10 \mathrm{~m}$ seems adequate.

- Thermal characteristics : the propagation of the solar heat wave is strongly dependent on the thermal conductivity of the surface layers and on the presence of heat sinks, such as pockets of ices, close to the surface. Observing thermal emission as the terminator crosses a surface element will therefore provide constraints on the subsurface structure. It would be highly desirable to obtain radiometric results at different wavelengths, so as to probe different depth scales. 


\section{2. COMETARY MATERIAL}

The characterization of cometary material is the primary science goal of the mission. It will be addressed by combining high quality investigations in the inner coma with ground truth obtained by the surface science package.

\subsubsection{Surface science}

Investigations of cometary material at the very surface of the nucleus are considered extremely important in combination with analyses in the inner coma. Obtaining ground truth information on physical, chemical and mineralogical characteristics for at least one site will provide unique insight on the conditions prevailing at the interface between cometary material in the nucleus and the cometary environment. It will also much improve the interpretation of remote sensing and inner coma investigations. The major science goals can be defined as follows :

- chemical composition of refractories and volatiles in bulk surface material : contrarily with coma investigations, which will provide analyzes on very small amounts of material, a surface package will provide information on the bulk composition (e.g. several tens of $\mathrm{cm}$ for gamma ray spectrometry). The characterization of the volatile and organic components is a particularly important goal, which can be addressed by evolved gas analyses. Obtaining the isotopic ratios of light elements represents a major technological challenge given the mass and power resources of a surface science package; this possibility should however be investigated given the high science priority.

- thermal and mechanical properties of surface material : with an accelerometer, a surface science package will also provide unique information on the mechanical properties of the cometary crust, which are at present totally unknown. Thermal probes will determine the temperature and conductivity of surface material, a key parameter for the thermal evolution of the nucleus during the diurnal and seasonal cycles. The potential of subsurface electromagnetic sounding and radio science using the link to the orbiter should also be evaluated.

Although a surface science package anywhere on the nucleus would provide a high science return, a site selection capability is desirable. If available, the preference should be given to active regions which are likely to present the largest concentrations of volatile material close to the surface.

\subsubsection{Investigations in the inner coma}

The ROSETTA mission scenario, and the relatively low activity of the target comets, make it possible to remain within a few $\mathrm{km}$ to a few $10 \mathrm{~km}$ of the nucleus until perihelion. These distances are far smaller than the few $1000 \mathrm{~km}$ at which extended gas sources have been observed for Halley. Gas species and even relatively volatile grains are likely to be very little disturbed during their travel from the cometary surface to the spacecraft. The major objectives of these investigations are the following : 
- Chemical and isotopic composition of grains : it will be possible to analyze several ten thousand grains in the inner coma in terms of their chemistry and the isotopic ratios of light elements $(\mathrm{H}, \mathrm{C}, \mathrm{N})$. Variations of several orders of magnitudes have been observed at a micrometer scale in candidate presolar grains from meteorites (see Fig. 2), which can be directly related to nucleosynthetic processes. Such large variations are well within the reach of a high resolution mass spectrometer. It will therefore be possible to characterize presolar components of cometary material, which are likely to be far more diverse than the highly refractory grains ( $\mathrm{SiC}$, diamonds) preserved in meteorites. The determination of the isotopic ratios for Oxygen, one of the most important nucleosynthetic tracers, represent a more difficult challenge since accuracies better than $1 \%$ are required over a wide dynamic range. It seems unlikely that the very high sensitivities required for noble gases or radiochronology will be available with space qualified instrumentation.

- Texture and elemental variations within dust grains : It will be possible to obtain high resolution images and elemental maps of dust grains by combining scanning electron microscopy with X-ray spectrometry. In combination with high resolution mass spectrometry, it will be possible to characterize presolar components as well as pristine condensates from the solar nebula. The texture and composition of cometary grains will also provide constraints on the link with interplanetary dust particles and stratospheric grains.

- Chemical and isotopic composition of gases in the inner coma : recent advances in the mass resolution of neutral and ion mass spectrometers will provide for gases the same level of information on the chemical and isotopic composition as that obtained on dust grains. Given the very short flight time, there should be a very close compositional relationship between the analyzed gases and the volatiles in the outer regions of the nucleus. This type of investigations is essential as the volatile component has been completely lost in stratospheric dust particles, the closest available equivalent to cometary material.

The long observation phase close to the nucleus (one year in the nominal mission) constitutes a tremendous asset for obtaining in the inner coma analyses of dust and gas which are representative of the outer layers of the nucleus. It will be possible to monitor the active regions during a large fraction of the activity cycle, hence to change the orbit so as to analyze material from each active region, and possibly from non active areas as well. The observation of compositional differences would be a strong argument in favor of the formation of the nucleus from the coalescence of subnuclei. The long observation time also leaves room for serendipity : if an outburst is observed, it may be possible to analyze material from a previously unexposed region. Finally, observing the evolution of active regions together with dust and gas activity will provide clues on the relationship between surface material and underlying material, as well as between material in the coma and surface material. 


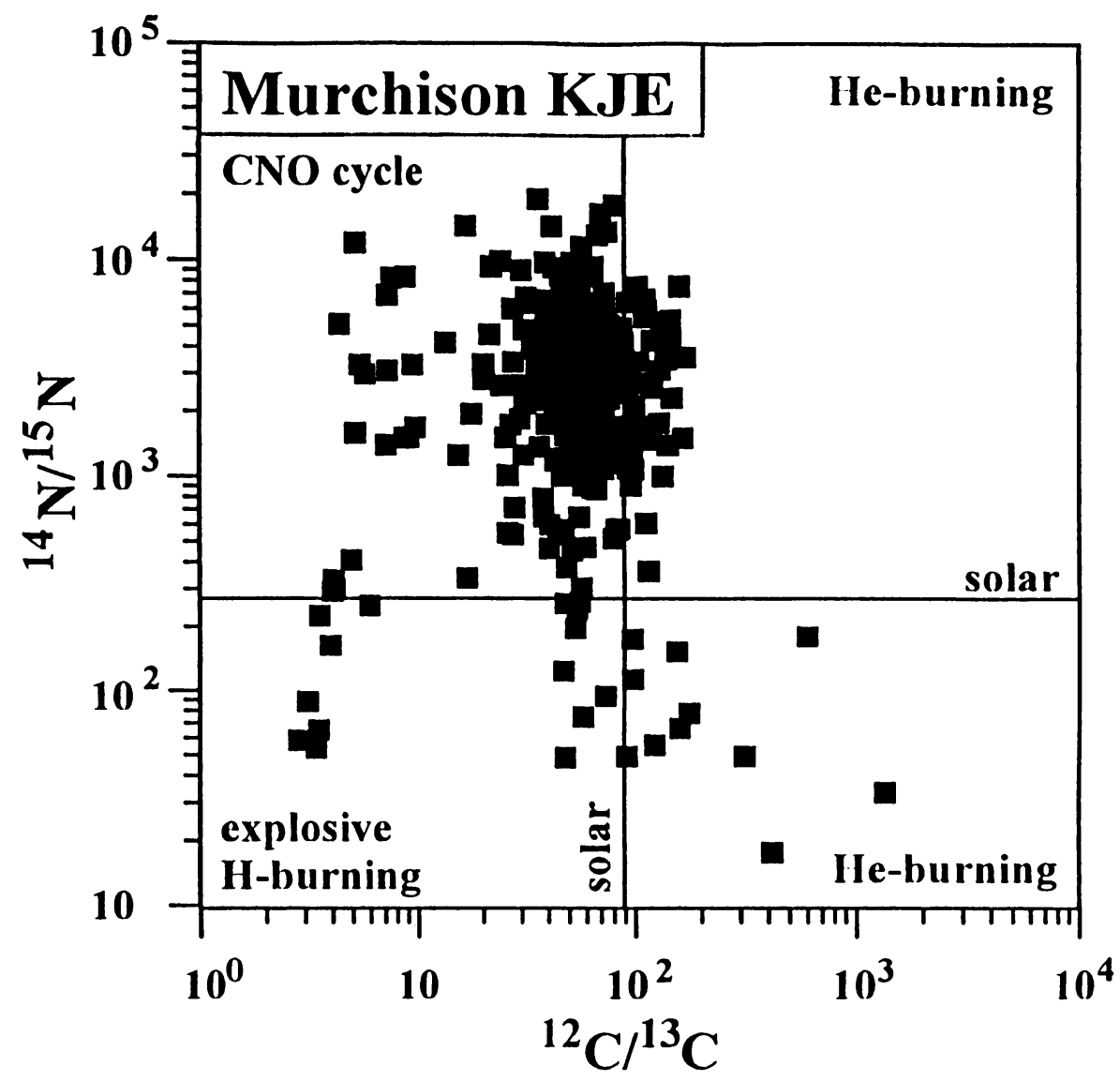

Fig. 2. Nitrogen and carbon-isotopic compositions of individual $\sim 1 \mu \mathrm{m}$ sized silicon carbide grains from the Murchison carbonaceous chondrite. The two lines labelled as "solar" indicate solar system ratios, dividing the plot into four quadrants for which the principal nucleosynthetic processes are indicated. Their anomalous isotopic composition indicate that the grains are of presolar origin. (Courtesy of Hoppe et al.)

\section{Cometary Physics}

While not dedicated mainly to the study of physical processes in the cometary environment, ROSETTA, with its more than one year of continuous observations, will provide high quality data on cometary processes. According to the mission scenario, the highest priority will be given to processes in the inner coma. The range of cometary processes is extremely wide, from solid state physics inside the nucleus to plasma physics in the outer coma. The major science goals can be very 
briefly summarized as follows :

- Temporal variations of cometary activity : as demonstrated by the Halley fly-bys and simultaneous ground observations, the relationship between the rotational state of the nucleus and the activity cycle is as yet not completely understood (see Rickman, this volume). ROSETTA will provide simultaneous observations of the evolution of active areas and the related activity. It will also be possible to relate outbursts (if any) to changes in surface configuration (e.g. ejection of part of the insulating mantle).

- Spatial anisotropies : detailed observations of dust and gas jets will be performed. Velocity vectors of dust grains impacting the spacecraft will be determined. It would be very useful to obtain remote sensing information on gas velocities using a high resolution sub-mm spectrometer.

- physico-chemical processes in the inner coma : observations of dust, gas and ionized species during more than one year in the inner coma will provide important information on parent molecules, the dust - gas interactions, and the processes through which parent molecules evolve into other neutral and ionized species.

- Interactions with the solar wind : At the beginning of the observation phase, it will be possible to investigate the interaction of the solar wind with the bare nucleus, then to observe this interaction during the growth phase of the coma. Excursions in the dust and plasma tail could be considered either in the nominal mission or during an extended mission, after perihelion.

\section{Asteroid Science with ROSETTA}

ROSETTA will perform at least one, possibly two fly-bys of asteroids in the main belt. These fly-bys will have similar characteristics to that already performed by GALILEO at Gaspra and Ida : a miss distance of a few $1000 \mathrm{~km}$, and a relative velocity of 6 to $15 \mathrm{~km} / \mathrm{s}$. The main goal of asteroid fly-bys with ROSETTA is to complement the first survey of the diversity of asteroids initiated by GALILEO, as the two visited objects were relatively small S-type asteroids. On these grounds, the highest priority should be given to carbonaceous asteroids ( $C$ or $D$ types), or very evolved asteroids (such as those of $\mathrm{V}$ or $\mathrm{M}$ types) which will not have been observed. These targets are also the most interesting in combination with the flybys of Gaspra and Ida to improve our understanding of the asteroid - meteorite relationship.

ROSETTA gives the possibility of observing two types of primitive bodies with the same remote sensing payload : the cometary nucleus which is the primary goal of the mission, and the asteroid(s) selected as fly-by target(s). It will therefore be possible to directly compare the two major classes of primitive solar system bodies. Indeed, the Halley fly-bys, then ground based observations, suggested similarities between cometary nuclei and the most primitive asteroids. On this basis, the priority for ROSETTA will be given among available targets to carbonaceous asteroids, the most likely to provide clues on the comet - asteroid relationship. 
TABLE III

ROSETTA MODEL PAYLOAD

ORBITER SPACECRAFT

\begin{tabular}{|l|c|c|}
\hline & Mass & Power \\
\hline \hline Remote Imaging System & $20 \mathrm{~kg}$ & $15 \mathrm{~W}$ \\
\hline $\begin{array}{l}\text { VIS and IR Mapping } \\
\text { Spectrometer }\end{array}$ & $23 \mathrm{~kg}$ & $15 \mathrm{~W}$ \\
\hline $\begin{array}{l}\text { Neutral Gas and Ion Mass } \\
\text { Spectrometer }\end{array}$ & $15 \mathrm{~kg}$ & $15 \mathrm{~W}$ \\
\hline Cometary Matter Analyser & $14 \mathrm{~kg}$ & $20 \mathrm{~W}$ \\
\hline $\begin{array}{l}\text { Scanning Electron } \\
\text { Microprobe }\end{array}$ & $13 \mathrm{~kg}$ & $22 \mathrm{~W}$ \\
\hline Dust Flux Analyser & $2.5 \mathrm{~kg}$ & $1 \mathrm{~W}$ \\
\hline Plasma Investigation & $2.5 \mathrm{~kg}$ & $3 \mathrm{~W}$ \\
\hline-9 & $90 \mathrm{~kg}$ & \\
\hline
\end{tabular}

Mass Allocation:

$96 \mathrm{~kg}$

Additional Instruments: Microwave Spectrometer, $\gamma$-ray Spectrometer,

Radar Mapper/Sounder, Radar Altimeter

\section{ROSETTA MODEL PAYLOAD NUCLEUS SURFACE INVESTIGATIONS}

\begin{tabular}{|l|c|c|}
\hline & Mass & Power \\
\hline \hline Gamma-Ray Spectrometer & $0.9 \mathrm{~kg}$ & $3 \mathrm{~W}$ \\
\hline $\begin{array}{l}\text { Alpha-Proton-X-Ray } \\
\text { Fluorescence } \\
\text { Spectrometer }\end{array}$ & $1 \mathrm{~kg}$ & $.5 \mathrm{~W}$ \\
\hline Neutron Spectrometer & $.4 \mathrm{~kg}$ & $1 \mathrm{~W}$ \\
\hline In-situ Imaging System & $1.5 \mathrm{~kg}$ & $2 \mathrm{~W}$ \\
\hline Accelerometer & $.2 \mathrm{~kg}$ & $.5 \mathrm{~W}$ \\
\hline Permittivity Probe & $.5 \mathrm{~kg}$ & $.2 \mathrm{~W}$ \\
\hline Evolved Gas Analyser & $3 \mathrm{~kg}$ & $5 \mathrm{~W}$ \\
\hline & $7.5 \mathrm{~kg}$ & \\
\hline
\end{tabular}

Additional Instruments: Instrument Deployment Device $1.5 \mathrm{~kg}+5 \mathrm{~kg}$, Surface Radar (Sounder) $3 \mathrm{~kg}$. 


\section{Model Scientific Payload}

\section{1. THE ROSETTA ORBITER}

The model payload which has been defined on the basis of the science objectives for the ROSETTA orbiter is divided in three groups (see Table III, top) :

- remote sensing instruments : an imaging system, with a navigation camera, a narrow angle camera (IFOV $=\mathbf{3 0}$ microradiants) and a wide angle camera (IFOV $=150$ microradiants), and a visible and infrared imaging spectrometer (IFOV $=500$ microradiants) extending from $0.3 \mu \mathrm{m}$ to $5 \mu \mathrm{m}$ (if possible higher in wavelengths) so as to cover major signatures of ices and minerals as well as reaching the thermal emission region.

- in-situ analyses instruments : a high resolution (a few 1000) spectrometer for dust particles; a high resolution (a few 1000) spectrometer for neutral and ionized species; a scanning electron microscope combined with $\mathrm{X}$-ray analyzer for dust grains, with a sub-micrometer spatial resolution.

- environment monitoring instruments : a dust flux analyzer providing the mass, flux and velocity vector of incoming dust particles; a plasma package including electron density measurements, a key parameter for the local physico-chemical processes.

Additional instruments have been considered for the payload. In particular, a microwave instrument can provide important radiometric information on the temperature of the nucleus down to a depth of a few $\mathrm{cm}$, much larger than that probed by the Visible - Near Infrared Imaging Spectrometer. It is possible to consider associated active microwave experiments, such as a high resolution microwave spectrometer for cometary gases, or an altimeter/sounder for obtaining information on the physical characteristics of the surface, and possibly the subsurface. The implementation of such instruments can be considered at various levels (e.g. additional electronic package associated with the telecommunications antenna, such as for CASSINI, or a dedicated small antenna). A gamma-ray spectrometer could also be considered, if the spacecraft can stay long periods of time within one radius of the nucleus.

\section{2. THE SURFACE SCIENCE PACKAGE}

The total mass allocation for the surface science package is $45 \mathrm{~kg}$, although there is a significant growth potential for all mission candidates. The proposed model payload (see Table III, bottom) includes an imaging system, to document the landing site. Two instruments dedicated to chemical analyses have been selected : a gamma ray spectrometer and an alpha-P-X-ray fluorescence spectrometer. Two instruments have been included for investigating organic and volatile material : an evolved gas analyzer, coupled with a gas chromatograph and/or mass spectrometer, and a neutron spectrometer (Hydrogen). An accelerometer will provide information on the mechanical characteristics of the surface material, while thermal and permittivity probes will determine major physical parameters. 
Additional instruments which were considered included a small, mobile instrument deployment device and a sub- surface sounding experiment, if it can fit mass and power constraints. The potential of radio science using the link to the orbiter will also be evaluated.

\section{Acknowledgments}

The ROSETTA mission in its new scenario was defined by the ROSETTA Study Team : A. Bar-Nun, A. Barucci, E. Bussoletti, A. Coradini, M. Coradini, L. Colangeli, P. Eberhardt, E. Grün, M. Hechler, H.U. Keller, J. Kissel, J. Klinger, Y. Langevin, R. Laurance, J.A.M. McDonnell, A. Milani, G. Picardi, C. Pillinger, G. Schwehm, D. Stöffler, H. Wänke. The ROSETTA report has been published by ESA as SP SCI(93)7. 